\title{
Predictive Equations for Maximum Respiratory Pressures of Women According to Body Mass
}

\author{
Dayla Sgariboldi MSc and Eli Maria Pazzianotto-Forti PhD
}

\begin{abstract}
BACKGROUND: The objective of the present study was to develop predictive equations for maximum respiratory pressures in women according to anthropometric characteristics. METHODS: This cross-sectional study included 156 women between ages 25 and 65 y with a body mass index (BMI) between 18.5 and $55 \mathrm{~kg} / \mathrm{m}^{2}$, who were evaluated for body mass, height, BMI, neck circumference, waist circumference, hip circumference, and waist/hip ratio. Respiratory muscle strength was assessed by measuring the maximum inspiratory pressure $\left(\mathbf{P}_{\text {Imax }}\right)$ and maximum expiratory pressure $\left(\mathbf{P}_{\text {Emax }}\right)$ with an analog vacuum manometer. For statistical analysis, the KolmogorovSmirnov test, Spearman correlation test, and stepwise multiple regression were used. The level of statistical significance was set at 5\% $(P<.05)$. RESULTS: Body mass, BMI, neck circumference, waist circumference, hip circumference, and waist/hip ratio showed significant and positive correlations with $P_{I m a x}$ and $P_{\text {Emax }}$ On the other hand, age and height showed no significant correlations with $\mathbf{P}_{\text {Imax }}$ and $\mathbf{P}_{\text {Emax }}$. In the regression analysis, the variables that correlated significantly with $\mathbf{P}_{\text {Imax }}$ and $\mathbf{P}_{\text {Emax }}$ were used. CONCLUSIONS: Body mass was the variable that best contributed to predicting maximum respiratory pressures values in women (11.70\% of the variations of the $P_{\text {Imax }}$ and $21.05 \%$ of the variations of the $P_{\text {Emax }}$ ). For $P_{\text {Imax }}$ measurements, the equation $-0.2 \times$ body mass -65.6 was established, and for $P_{\text {Emax }}$, the equation $0.3 \times$ body mass +66.4 was used. It is suggested that the predictive equations developed in this study can be used in the interpretation of the assessment of respiratory muscle strength in morbidly obese women $25-65$ y of age. Key words: women; obesity; respiratory muscle; muscle strength; reference values; physical therapy. [Respir Care 2016;61(4):468-474. (C) 2016 Daedalus Enterprises]
\end{abstract}

\section{Introduction}

Obesity has been regarded as a public health problem for some time, and it is currently becoming a worldwide epidemic. In $2008,>1.4$ billion adults were overweight, 300 million of whom were women. ${ }^{1}$ In addition to promoting the

The authors are affiliated with the Graduate Program in Physical Therapy and Human Movement Sciences, Universidade Metodista de Piracicaba (UNIMEP), Piracicaba, São Paulo, Brazil.

This work was supported by Fundação de Amparo à Pesquisa do Estado de São Paulo (FAPESP), São Paulo, Brazil, process no. 13/06334-8. The authors have disclosed no conflicts of interest.

Correspondence: Eli Maria Pazzianotto-Forti PhD, Rodovia do Açúcar, 156 Km Taquaral CEP, 13400-911, Piracicaba-SP, Brazil. E-mail: empforti@unimep.br.

DOI: $10.4187 /$ respcare.04204 development of comorbidities, ${ }^{2}$ obesity can modify respiratory muscle strength. ${ }^{3}$ However, no consensus has been reached in the literature concerning the behavior of the respiratory muscles in the presence of increased body mass index (BMI). ${ }^{4-6}$

According to Magnani and Cataneo, ${ }^{5}$ individuals with obesity have respiratory muscle dysfunction due to changes in the relationship between the lung, chest wall, and diaphragm muscle, which in turn alter respiratory mechanics and gas exchange. It is believed that these changes cause overload in the respiratory muscles, increasing the mechanical work involved in respiration. This occurs due to the increased deposition of fat in the chest wall, which increases the body mass that needs to be moved during the respiratory cycle. This overload can cause an increase in the activity of respiratory muscles and causes the training effect and, in the long term, may increase respiratory muscle strength. $5,7,8$

One of the ways of evaluating respiratory muscle strength is by measuring the maximum respiratory pressure pro- 
duced during maximum inspirations and expirations, thus characterizing the strength of the inspiratory and expiratory muscles. ${ }^{9}$ Based on the values obtained by measuring the maximum respiratory pressures, it is possible to calculate predicted values of normality through mathematical equations.

Several authors ${ }^{10-12}$ have determined reference values by means of equations considering sex and age. In a study of healthy sedentary individuals between 20 and $89 \mathrm{y}$ old, Simões et al $^{13}$ investigated the relationship of maximum respiratory pressures with age, height, and body mass and proposed predictive equations. They showed that, for women, age and body mass had a negative influence on measures of maximum respiratory pressures; however, it is worth noting that the BMI of the studied population was $<30 \mathrm{~kg} / \mathrm{m}^{2}$.

Pazzianotto-Forti et al ${ }^{14}$ evaluated the behavior of respiratory muscle strength in morbidly obese individuals using 3 different predictive equations and found 3 different results (predicted values) for the same value obtained. This suggests that the existing equations in the literature are not able to provide a reliable prediction of respiratory muscle strength for the morbidly obese and justifies the inconclusive results found in the literature on respiratory muscle strength in this population.

According to Harik-Khan et al, ${ }^{15}$ respiratory muscle strength is correlated with age, sex, weight, height, and body surface area. Given these findings, the authors developed a predictive equation for measurements of maximum inspiratory pressures $\left(\mathrm{P}_{\text {Imax }}\right)$, taking into account sex and height as well as body mass. However, we did not find predictive values for expiratory muscle strength according to body mass in the literature, emphasizing the need for the development of predictive equations to enhance the reliability and interpretation of the behavior of the respiratory muscles in the presence of obesity.

Due to the influence of anthropometric characteristics on respiratory muscle strength and considering the lack of predictive equations for respiratory muscle strength in morbidly obese women, ${ }^{10-13}$ the aim of this study was to develop predictive equations for maximum respiratory pressures in Brazilian women age 25-65 y according to body mass.

\section{Methods}

\section{Subjects}

Recruitment. This was a cross-sectional study consisting of 156 adult women, who were informed about the objectives of the study and signed a consent form. The study was approved by the Research Ethics Committee of Universidade Metodista de Piracicaba (UNIMEP), Piracicaba, São Paulo, Brazil (protocol number 49/12).

\section{QUICK LOOK}

\section{Current knowledge}

Due to the influence of anthropometric characteristics on respiratory muscle strength and considering the lack of predictive equations for respiratory muscle strength in morbidly obese women, there is a need for the development of predictive equations to enhance the reliability and interpretation of the behavior of the respiratory muscles in the presence of obesity.

\section{What this paper contributes to our knowledge}

Given that to date, no study has provided maximum respiratory pressures specific for the obese and morbidly obese populations or indicated the most appropriate equations available in the literature, these results will be useful in understanding and assessing the behavior of respiratory muscle strength in obesity and will also assist in the development of treatments to maintain and improve the strength of these muscles.

The sample size calculation was based on a pilot study that aimed to evaluate the influence of age and anthropometric characteristics on respiratory muscle strength. A significant correlation between BMI and $\mathrm{P}_{\text {Imax }}$ was considered. The value of $r=0.35$ was used for the calculation because it was the strongest correlation found between BMI and $\mathrm{P}_{\mathrm{Imax}}$. The linear correlation test, adopting a statistical power of $95 \%$ and an $\alpha$ of 0.05 , was also used. Thus, a minimum of 101 subjects was determined. The processing of the sample size calculation was performed using BioEstat 5.3 (Instituto de Desenvolvimento Sustentável Mamirauá, Belém, Brazil). Then 101 subjects were divided into 16 groups according to age and BMI. For homogenization of the groups regarding the number of subjects, each group had at least 6 subjects.

Obese and morbidly obese women were screened in a treatment clinic of obesity. Eutrophic and overweight women were recruited in the community by invitation to participate in the study.

Inclusion Criteria. The inclusion criteria were women with a BMI between 18.5 and $55 \mathrm{~kg} / \mathrm{m}^{2}$, age between 25 and $65 \mathrm{y}$, and sedentary lifestyle.

Exclusion Criteria. The exclusion criteria were as follows: presence of comorbidities, such as decompensated hypertension and diabetes; cardiovascular or pulmonary disease; presence of alterations in the thoracic and/or abdominal region; respiratory dynamics alterations; smoking; and inability to perform the assessments. All experimental procedures were performed in the Laboratory for 


\section{Respiratory Pressures and Body Mass}

Assessment and Intervention in Cardiorespiratory Physiotherapy of the university.

\section{Clinical Assessment}

After anamnesis and clinical history, anthropometric measurements were taken. To measure body mass, the subjects stood without shoes or heavy clothing on a digital scale (Welmy, Santa Bárbara D’Oeste, Brazil) calibrated with maximum capacity of $300 \mathrm{~kg}$ and $100 \mathrm{~g}$ resolution. Height was measured with the scale's stadiometer with resolution in millimeters.

The calculation of BMI was obtained by the equation, body mass $/$ height $^{2}\left(\mathrm{~kg} / \mathrm{m}^{2}\right)$. The circumferences were measured in centimeters using a non-elastic tape measure. Neck circumference was measured at the cricoid cartilage ${ }^{16}$; waist circumference was measured at the midpoint between the margin of the last rib and the upper margin of the iliac crest; hip circumference was measured at the greater trochanter of femur ${ }^{17}$; and with the measures of waist circumference and hip circumference, the waist/hip ratio was obtained.

For the assessment of respiratory muscle strength, maximum respiratory pressures were measured using an analog vacuum manometer (Criticalmed, Rio de Janeiro, Brazil), with an operating range of $\pm 300 \mathrm{~cm} \mathrm{H}_{2} \mathrm{O}$. The mouthpiece has a 2-mm leak hole to prevent glottic closure during the maneuver of $\mathrm{P}_{\mathrm{Imax}}$ and reduce the use of facial muscles during the $\mathrm{P}_{\mathrm{Emax}}$ maneuver.

The $\mathrm{P}_{\text {Imax }}$ was measured from residual volume, and $\mathrm{P}_{\mathrm{Emax}}$ was measured from total lung capacity. A 1-min interval was allowed between efforts. To perform these measurements, subjects were instructed to remain seated and use a nose clip. All subjects performed $\geq 3$ technically acceptable and reproducible efforts (ie, without perioral air leakage, sustained for at least $2 \mathrm{~s}$, and with similar values [within 10\%]). For data analysis, the highest value was used. ${ }^{11}$

\section{Data Analysis}

The distribution of data was verified by the Kolmogorov-Smirnov test, followed by the Spearman correlation test to assess possible relationships of variables with $\mathrm{P}_{\text {Imax }}$ and $\mathrm{P}_{\text {Emax }}$. Stepwise multiple regression was used to develop predictive equations for the maximum respiratory pressures. Only variables that showed significant correlations with $\mathrm{P}_{\text {Imax }}$ and $\mathrm{P}_{\text {Emax }}$ were included in the model. The level of statistical significance was set at $5 \%(P<.05)$. All statistical procedures were performed using the statistical programs SPSS 17.0 (SPSS, Chicago, Illinois) and R 3.1.0 (R Foundation for Statistical Computing, Vienna, Austria).

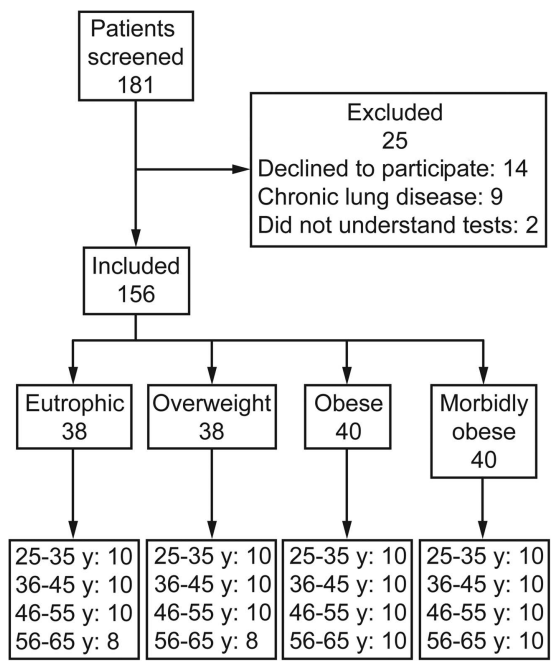

Fig. 1. Flow chart.

Table 1. Anthropometric Characteristics and Measurements of the Circumference of the Neck, Waist, and Hip and Waist/Hip Ratio of the 156 Subjects Studied, Distributed in Groups According to Body Mass Index

\begin{tabular}{|c|c|c|c|c|}
\hline Variables & Eutrophic & Overweight & Obese & $\begin{array}{l}\text { Morbidly } \\
\text { Obese }\end{array}$ \\
\hline Age, y & $43.8 \pm 11.2$ & $44 \pm 11$ & $45.8 \pm 10.8$ & $44.2 \pm 10.3$ \\
\hline Body mass, kg & $57.8 \pm 5.8$ & $71 \pm 5.7$ & $89.8 \pm 12.6$ & $116.5 \pm 16.7$ \\
\hline Height, m & $1.6 \pm 0.06$ & $1.6 \pm 0.06$ & $1.6 \pm 0.06$ & $1.6 \pm 0.06$ \\
\hline BMI, $\mathrm{kg} / \mathrm{m}^{2}$ & $22.3 \pm 1.8$ & $27.2 \pm 1.4$ & $35.3 \pm 3.4$ & $46.1 \pm 4.8$ \\
\hline $\mathrm{NC}, \mathrm{cm}$ & $31.3 \pm 2.3$ & $33.8 \pm 2$ & $38 \pm 2.9$ & $44.5 \pm 2.8$ \\
\hline $\mathrm{WC}, \mathrm{cm}$ & $90 \pm 6.9$ & $91.2 \pm 8.6$ & $109.7 \pm 9.5$ & $127.2 \pm 13$ \\
\hline $\mathrm{HC}, \mathrm{cm}$ & $96.2 \pm 5.6$ & $106.4 \pm 4.6$ & $119.7 \pm 11.1$ & $136.2 \pm 13.1$ \\
\hline $\mathrm{W} / \mathrm{H}$ & $0.8 \pm 0.09$ & $0.9 \pm 0.07$ & $0.9 \pm 0.07$ & $0.9 \pm 0.08$ \\
\hline $\begin{array}{l}\text { Data are mean } \pm \mathrm{SD} \\
\mathrm{BMI}=\text { body mass in } \\
\mathrm{NC}=\text { neck circumfe } \\
\mathrm{WC}=\text { waist circumf } \\
\mathrm{HC}=\text { hip circumfere } \\
\mathrm{W} / \mathrm{H}=\text { waist } / \text { hip rati }\end{array}$ & $\begin{array}{l}\text { ndex } \\
\text { erence } \\
\text { ference } \\
\text { ence } \\
\text { io }\end{array}$ & & & \\
\hline
\end{tabular}

\section{Results}

\section{Subjects}

One hundred eighty-one subjects were screened, 25 of whom were excluded according to the established criteria. Therefore, 156 women, divided for convenience into groups according to BMI and age, were evaluated as shown in the flow diagram (Fig. 1).

\section{Findings From Clinical Assessment}

Table 1 shows the data for the age, anthropometric characteristics, and body fat distribution of the sample, divided by 


\section{Respiratory Pressures and Body Mass}

Table 2. Maximal Respiratory Pressures Obtained From 156 Subjects Studied

\begin{tabular}{lcrrr}
\hline \hline & Eutrophic & Overweight & Obese & \multicolumn{1}{c}{$\begin{array}{c}\text { Morbidly } \\
\text { Obese }\end{array}$} \\
\hline $\mathrm{P}_{\text {Imax }}, \mathrm{cm} \mathrm{H}_{2} \mathrm{O}$ & $-77.9 \pm 16.2$ & $-82.5 \pm 16.6$ & $-85.9 \pm 14.7$ & $-93.9 \pm 15.7$ \\
$\mathrm{P}_{\text {Emax }}, \mathrm{cm} \mathrm{H}_{2} \mathrm{O}$ & $84.2 \pm 16$ & $90.2 \pm 14.7$ & $99.7 \pm 16.7$ & $104.7 \pm 18.1$
\end{tabular}

Data are mean \pm SD

$\mathrm{P}_{\mathrm{Imax}}=$ maximum inspiratory pressure

$\mathrm{P}_{\text {Emax }}=$ maximum expiratory pressure

BMI. Table 2 shows the values for the maximum respiratory pressures collected from the 156 subjects. Figures 2 and 3 show the results of the correlations of the maximum respiratory pressures with anthropometric characteristics.

Age and height had no significant correlations with $\mathrm{P}_{\mathrm{Imax}}$ $(P=.96$ and $P=.70)$ or $\mathrm{P}_{\mathrm{Emax}}(P=.14$ and $P=.20)$. On the other hand, body mass, BMI, neck circumference, waist circumference, hip circumference, and waist/hip ratio showed significant and positive correlations with $\mathrm{P}_{\mathrm{Imax}}$ and $\mathrm{P}_{\text {Emax }}(P<.05)$.

The variables that showed positive correlations with $\mathrm{P}_{\text {Imax }}$ and $\mathrm{P}_{\text {Emax }}$ were included in the stepwise multiple regression for the development of predictive equations for maximum respiratory pressures. Body mass was the variable that best contributed to variations in the maximum respiratory pressures. All variables added together explained $15.16 \%$ of the variations of the $\mathrm{P}_{\text {Imax }}$ and $24.69 \%$ of the variations of $\mathrm{P}_{\text {Emax }}$. Body mass alone explains $11.70 \%$ of the variations of the $\mathrm{P}_{\mathrm{Imax}}$ and $21.05 \%$ of the variations of $\mathrm{P}_{\mathrm{Emax}}$. Based on these results, the new equations were developed for maximum respiratory pressures, taking into account body mass.

Table 3 shows the predictive equations model proposed for maximum respiratory pressures in women according to body mass. These results are based on the stepwise multiple regression. Tables 4 and 5 show the stepwise multiple regression analyses.

\section{Discussion}

The study reveals that body mass showed the best contribution to the variations of maximum respiratory pressures in women. Therefore, body mass was included in predictive equations for $\mathrm{P}_{\text {Imax }}$ and $\mathrm{P}_{\text {Emax }}$ prepared in this study.

Other studies ${ }^{15,18}$ found that body mass was a positive predictor of respiratory muscle strength in both sexes. According to Arora and Rochester, ${ }^{19}$ changes in body mass could affect diaphragmatic muscle mass influencing respiratory muscle performance and thus the maximum respiratory pressures.

Santiago-Recuerda et $\mathrm{a}^{20}$ have reported that the increase in respiratory muscle strength due to the increase in body mass happens through the reversal of the muscle fiber type (ie, larger quantities of type II fibers compared with type I fibers). This is explained by the adaptation to chronic overload that accompanies obesity. Wannamethee et $\mathrm{al}^{21}$ and Sutherland et $\mathrm{al}^{22}$ reported that the increase in respiratory muscle strength is due to the increase in lean mass, hence the importance of the presence of body mass in the predictive equations, particularly for assessing respiratory muscle strength in morbid obesity.

The predictive equations available in the literature ${ }^{10-13}$ demonstrate that age, body mass, height, and sex variables have an influence on the values for maximum respiratory pressures. However, it is noteworthy that, in most of these predictive equations, body mass was not used as a component because the regression analysis only shows predictive power for age and height. It should be emphasized that these equations were obtained in eutrophic populations and not in obese people. Therefore, the real contribution of obesity to respiratory muscle strength as an independent variable could not be evaluated and interpreted, ${ }^{23}$ making the behavior of respiratory muscle strength in obesity inconclusive and controversial. ${ }^{4-6}$

In this study, the variables age and height showed no correlations with the maximum respiratory pressures; thus, they were not included in the linear regression model. This may have been due to the homogeneity of the groups with regard to these variables, unlike in the studies of Black and Hyatt, ${ }^{10}$ Neder et al, ${ }^{11}$, Costa et al, ${ }^{12}$ and Simões et al, ${ }^{13}$ in which these variables showed a negative predictive importance for maximum respiratory pressures. One explanation for this may be the differences in age between the samples, which ranged from 20 to $86 \mathrm{y}$. These results may be due to the sarcopenia associated with aging, ${ }^{24}$ whereas in the present study, women up to $65 \mathrm{y}$ old were assessed, who were probably not affected by the changes of aging.

Therefore, predictive equations of $\mathrm{P}_{\mathrm{Imax}}$ and $\mathrm{P}_{\mathrm{Emax}}$ are possible alternatives and can be used for the obese and morbidly obese population and thus direct conclusions about the interpretation of respiratory muscle strength in obesity. That is especially relevant to morbidly obese candidates for abdominal surgery, ${ }^{25}$ given that respiratory muscle dysfunction is the major cause of pulmonary complications after surgical procedures. ${ }^{26}$ For obese individuals, independent of surgical procedures, respiratory muscle dysfunction may lead to hypoventilation, dyspnea, and exercise intolerance and, in extreme cases, respiratory insufficiency. ${ }^{27,28}$

Given that to date no study has provided maximum respiratory pressures specific for the obese and morbidly obese populations, or indicated the most appropriate equations available in the literature, we suggest that the predictive equations developed in this study be used in the interpretation of respiratory muscle strength assessments in morbidly obese women between the ages of 25 and $65 \mathrm{y}$. 

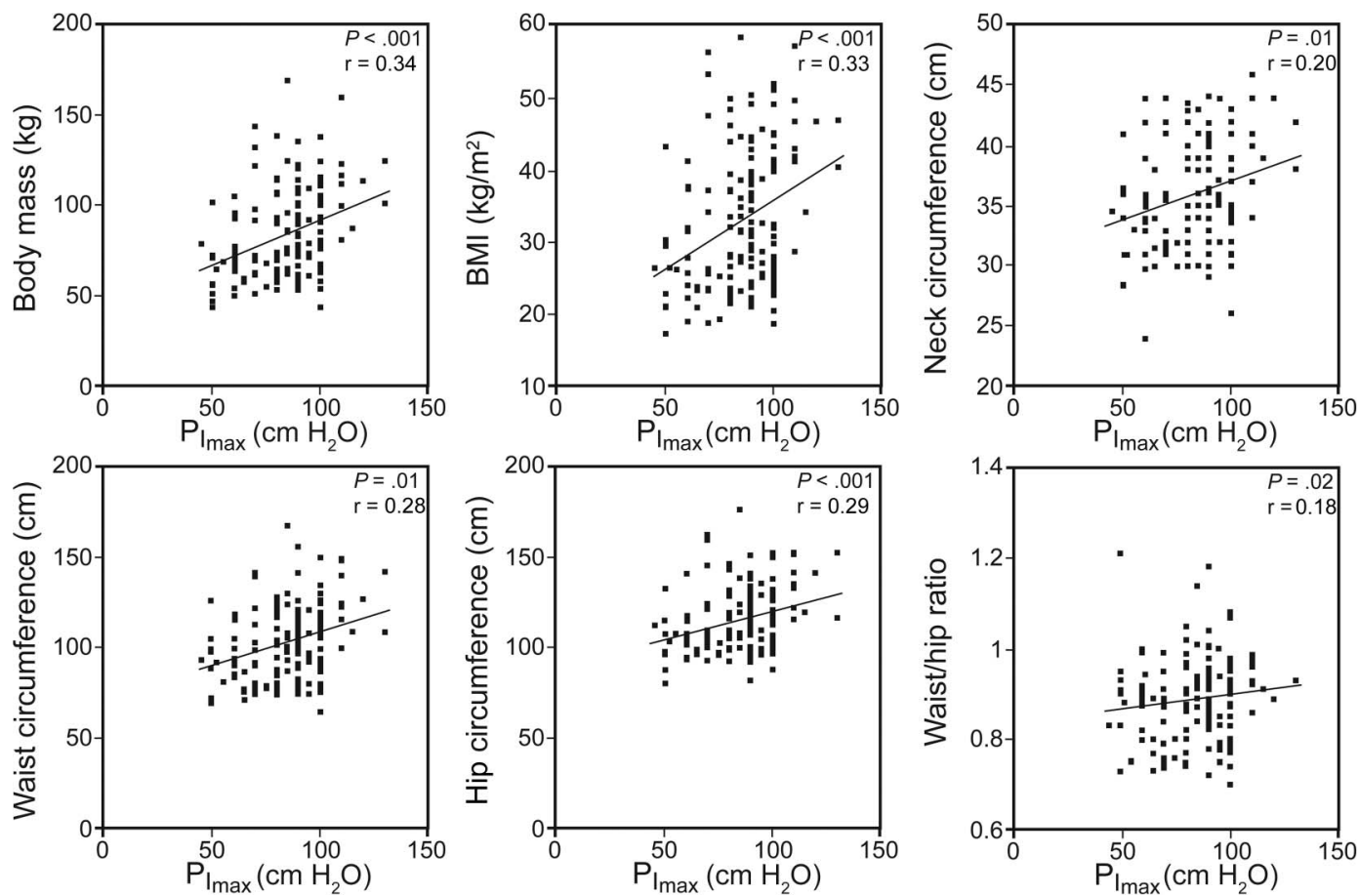

Fig. 2. Correlations between $P_{I \max }$ and anthropometric variables.
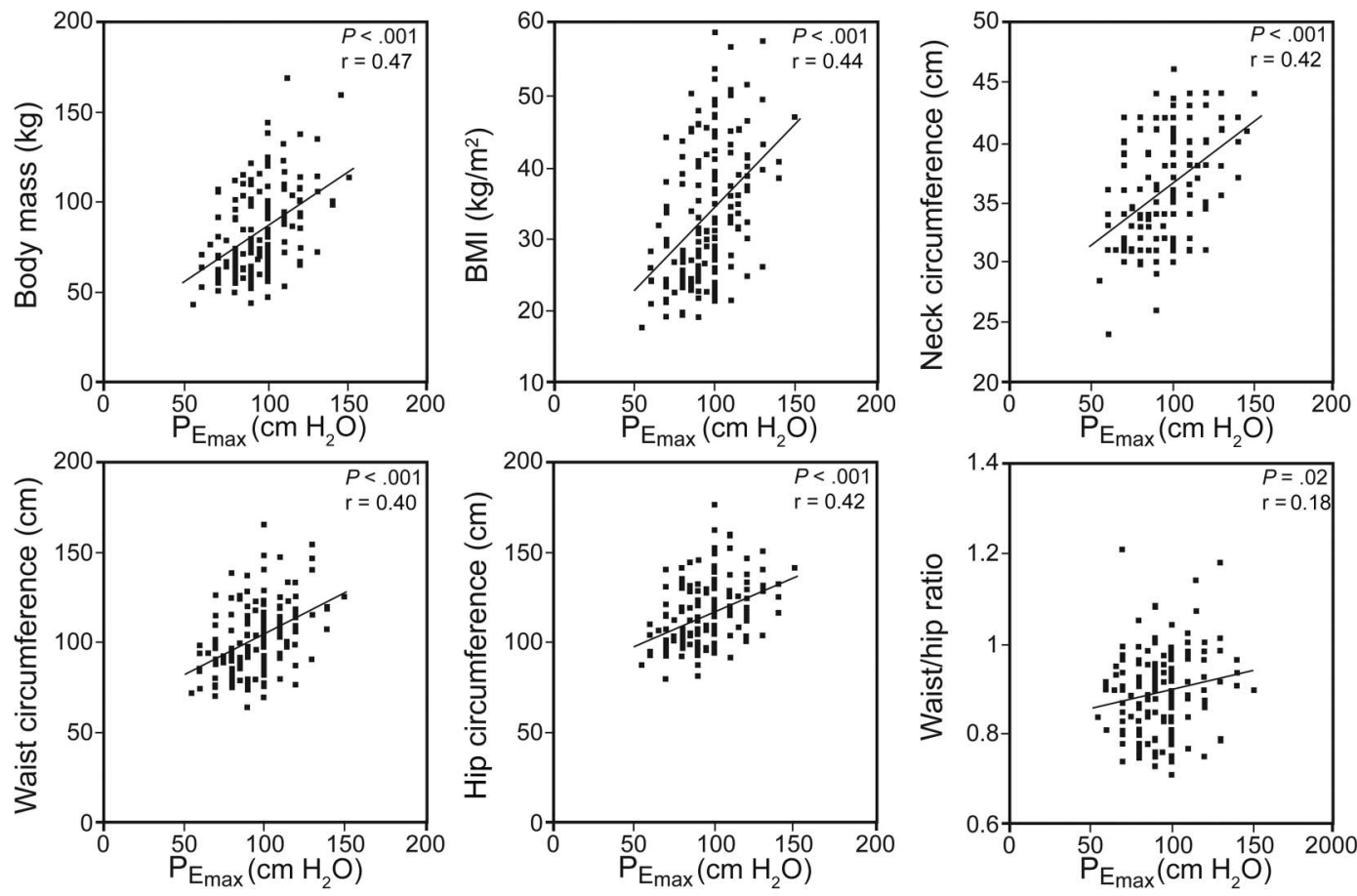

Fig. 3. Correlations between $P_{E \max }$ and anthropometric variables.

\section{Study Limitations}

The study was conducted by means of BMI classification to identify eutrophic, overweight, obese, and mor- bidly obese subjects. Although BMI is recommended by the World Health Organization due to its convenience and affordability, we do not reject the contribution of a more reliable assessment to measure lean mass and body 


\section{Respiratory Pressures and Body Mass}

Table 3. Predictive Equations for Maximum Respiratory Pressures in Brazilian Women Age 25-65 y According to Body Mass

\begin{tabular}{|c|c|c|c|c|c|c|}
\hline & Equation & Adjusted $\mathrm{R}^{2}$ & MSE & Lower Limit 95\% CI & Upper Limit 95\% CI & $P$ \\
\hline $\mathrm{P}_{\text {Imax }}, \mathrm{cm} \mathrm{H}_{2} \mathrm{O}$ & $-0.2 \times$ weight -65.6 & 0.11 & 15.94 & -97.1 & -34.1 & $<.001$ \\
\hline $\mathrm{P}_{\text {Emax }}, \mathrm{cm} \mathrm{H}_{2} \mathrm{O}$ & $0.3 \times$ weight +66.4 & 0.20 & 16.37 & 34.1 & 98.8 & $<.001$ \\
\hline \multicolumn{7}{|c|}{$\begin{array}{l}\mathrm{P}_{\operatorname{Imax}}=\text { maximal inspiratory pressure } \\
\mathrm{P}_{\text {Emax }}=\text { maximal expiratory pressure } \\
\text { MSE = mean square error }\end{array}$} \\
\hline
\end{tabular}

Table 4. Regression Analysis Considering Maximum Inspiratory Pressure as a Dependent Variable

\begin{tabular}{|c|c|c|c|c|}
\hline Dependent variable: $P_{\text {Imax }}$ & $\mathrm{r}$ & $\mathrm{R}^{2}, \%$ & $P$ & Excluded Variable \\
\hline Age, body mass, height, BMI, NC, WC, $\mathrm{HC}$, and $\mathrm{W} / \mathrm{H}$ & 0.39 & 15.16 & .002 & \\
\hline Body mass, height, BMI, NC, WC, $\mathrm{HC}$, and W/H & 0.39 & 15.09 & .001 & Age \\
\hline Body mass, BMI, NC, WC, HC, and W/H & 0.38 & 14.30 & .001 & Height \\
\hline Body mass, BMI, NC, WC, and $\mathrm{HC}$ & 0.36 & 12.74 & .001 & $\mathrm{~W} / \mathrm{H}$ \\
\hline Body mass, BMI, WC, and $\mathrm{HC}$ & 0.35 & 12.28 & $<.001$ & $\mathrm{NC}$ \\
\hline Body mass, BMI, and WC & 0.34 & 11.84 & $<.001$ & $\mathrm{HC}$ \\
\hline Body mass and BMI & 0.34 & 11.79 & $<.001$ & WC \\
\hline Body mass & 0.34 & 11.70 & $<.001$ & BMI \\
\hline $\begin{array}{l}\mathrm{P}_{\mathrm{Imax}}=\text { maximum inspiratory pressure } \\
\mathrm{BMI}=\text { body mass index } \\
\mathrm{NC}=\text { neck circumference } \\
\mathrm{WC}=\text { waist circumference } \\
\mathrm{HC}=\text { hip circumference } \\
\mathrm{W} / \mathrm{H}=\text { waist } / \text { hip ratio }\end{array}$ & & & & \\
\hline
\end{tabular}

Table 5. Regression Analysis Considering Maximum Expiratory Pressure as a Dependent Variable

\begin{tabular}{|c|c|c|c|c|}
\hline Dependent Variable: $\mathrm{P}_{\text {Emax }}$ & $\mathrm{r}$ & $\mathrm{R}^{2}, \%$ & $P$ & Excluded Variable \\
\hline Age, body mass, height, BMI, NC, WC, $\mathrm{HC}$, and $\mathrm{W} / \mathrm{H}$ & 0.50 & 24.69 & $<.001$ & \\
\hline Age, body mass, BMI, NC, WC, $\mathrm{HC}$, and W/H & 0.49 & 24.32 & $<.001$ & Height \\
\hline Body mass, BMI, NC, WC, $\mathrm{HC}$, and W/H & 0.49 & 23.65 & $<.001$ & Age \\
\hline Body mass, BMI, NC, WC, and $\mathrm{HC}$ & 0.48 & 22.92 & $<.001$ & $\mathrm{~W} / \mathrm{H}$ \\
\hline Body mass, BMI, NC, and WC & 0.47 & 22.30 & $<.001$ & $\mathrm{HC}$ \\
\hline Body mass, BMI, and NC & 0.47 & 22.05 & $<.001$ & WC \\
\hline Body mass and BMI & 0.46 & 21.05 & $<.001$ & $\mathrm{NC}$ \\
\hline Body mass & 0.46 & 21.05 & $<.001$ & BMI \\
\hline $\begin{array}{l}\mathrm{P}_{\mathrm{Emax}}=\text { maximum expiratory pressure } \\
\mathrm{BMI}=\text { body mass index } \\
\mathrm{NC}=\text { neck circumference } \\
\mathrm{WC}=\text { waist circumference } \\
\mathrm{HC} \text { = hip circumference } \\
\text { W/H = waist/hip ratio }\end{array}$ & & & & \\
\hline
\end{tabular}

fat. The absence of men in the present study limits the results to the female sex.

\section{Clinical Relevance}

The use of the equations proposed in this study will be useful in understanding and assessing the behavior of respiratory muscle strength in obesity. These will also assist the development of treatments to maintain and improve the strength of these muscles, thus preventing respiratory complications as a result of surgery, pulmonary diseases, and aging, reducing dyspnea, and increasing tolerance to exercise. Finally, these treatments might improve health and quality of life and reduce mortality in this population. 


\section{Respiratory Pressures and Body Mass}

\section{REFERENCES}

1. World Health Organization. Media centre: obesity and overweight 2012. http://www.who.int/mediacentre/factsheets/fs311/en/. Accessed November 9, 2015.

2. Yurcisin BM, Gaddor MM, DeMaria EJ. Obesity and bariatric surgery. Clin Chest Med 2009;30(3):539-553, ix.

3. Sood A. Altered resting and exercise respiratory physiology in obesity. Clin Chest Med 2009;30(3):445-454, vii.

4. Ochs-Balcom HM, Grant BJB, Muti P, Sempos CT, Freudenheim JL, Trevisan M, et al. Pulmonary function and abdominal adiposity in the general population. Chest 2006;129(4):853-862.

5. Magnani KL, Cataneo AJM. Respiratory muscle strength in obese individuals and influence of upper-body fat distribution. São Paulo Med J 2007;125(4):215-219.

6. Teixeira CA, Dos Santos JE, de Silva GA, Souza EST, Martinez JAB. Prevalência de dispnéia e possíveis mecanismos fisiopatológicos envolvidos em indivíduos com obesidade graus 2 e 3. J Bras Pneumol 2007;33(1):28-35.

7. Costa D, Sampaio LMM, Lorenzzo VAP, Jamami M, Damaso AR. Avaliação da força muscular respiratória e amplitudes torácicas e abdominais após RFR em indivíduos obesos. Rev Latino-Am Enferm 2003;11(2):156-160. doi: 10.1590/S0104-11692003000200003.

8. Paisani DM, Chiavegato LD, Faresin SM. Volumes, capacidades pulmonares e força muscular respiratória no pós-operatório de gastroplastia. J Bras Pneumol 2005;31(2):125-132. doi: 1590/S180637132005000200007.

9. Mangelsdorff G, Borzone G, Leiva A, Martínez A, Lisboa C. Strength of inspiratory muscles in chronic heart failure and chronic pulmonary obstructive disease [Article in Spanish]. Rev Med Chil 2001; 129(1):51-59.

10. Black LF, Hyatt RE. Maximal respiratory pressures: normal values and relationship to age and sex. Am Rev Respir Dis 1969;99(5):696702.

11. Neder JA, Andreoni S, Lerario MC, Nery LE. Reference values for lung function tests. II. Maximal respiratory pressures and voluntary ventilation. Braz J Med Biol Res 1999;32(6):719-727.

12. Costa D, Gonçalves HA, Lima LP, Ike D, Cancelliero KM, Montebelo MIL. Novos valores de referência para pressões respiratórias máximas na população brasileira. J Bras Pneumol 2010;36(3):306312 .

13. Simões RP, Deus APL, Auad MA, Dionísio J, Mazzonetto M, BorghiSilva A. Maximal respiratory pressure in healthy 20 to 89 year-old sedentary individuals of central São Paulo State. Rev Bras Fisioter 2010;14(1):60-67.

14. Pazzianotto-Forti EM, Peixoto-Souza FS, Piconi-Mendes C, RaseraJunior I, Barbalho-Moulim M. Comportamento da força muscular respiratória de obesas mórbidas por diferentes equações preditivas. Rev Bras Fisioter 2012;16(6):479-486.
15. Harik-Khan RI, Wise RA, Fozard JL. Determinants of maximal inspiratory pressure: the Baltimore Longitudinal Study of Aging. Am J Respir Crit Care Med 1998;158(5):1459-1464.

16. Gonçalves MJ, do Lago STS, Godoy Ede P, Fregonezi GAF, Bruno SS. Influence of neck circumference on respiratory endurance and muscle strength in the morbidly obese. Obes Surg 2011;21(8):12501256.

17. Sievenpiper JL, Jenkins DJ, Josse RG, Leiter LA, Vuksan V. Simple skinfold-thickness measurements complement conventional anthropometric assessments in predicting glucose tolerance. Am J Clin Nutr 2001;73(3):567-573.

18. Leech JA, Ghezzo H, Stevens D, Becklake MR. Respiratory pressures and function in young adults. Am Rev Respir Dis 1983;128(1): 17-23.

19. Arora NS, Rochester DF. Respiratory muscle strength and maximal voluntary ventilation in undernourished patients. Am Rev Respir Dis 1982;126(1):5-8.

20. Santiago-Recuerda A, Gómez-Terreros FJ, Caballero P, Martin-Duce A, Soleto MJ, Vesperinas G, et al. Relationship between the upper airway and obstructive sleep apnea-hypopnea syndrome in morbidly obese women. Obes Surg 2007;17(5):689-697.

21. Wannamethee SG, Shaper AG, Whincup PH. Body fat distribuition, body composition, and respiratory function in elderly men. Am J Clin Nutr 2005;82(5):996-1003.

22. Sutherland TJT, Goulding A, Grant AM, Cowan JO, Williamson A, Williams SM, et al. The effect of adiposity measured by dual-energy X-ray absorptiometry on lung function. Eur Respir J 2008;32(1):8591.

23. Rubinstein I, Zamel N, DuBarry L, Hoffstein V. Airflow limitation in morbidly obese, nonsmoking men. Ann Intern Med 1990;112(11): 828-832.

24. Watsford ML, Murphy AJ, Pine MJ. The effects of ageing on respiratory muscle function and performance in older adults. J Sci Med Sport 2007;10(1):36-44.

25. Castello V, Simões RP, Bassi D, Mendes RG, Borghi-Silva, A. Força muscular respiratória é marcantemente reduzida em mulheres obesas mórbidas. Arq Med ABC 2007;32(2):74-77.

26. Barbalho-Moulim MC, Miguel GPS, Forti EM, Campos Fdo A, Costa D. Effects of preoperative inspiratory muscle training in obese women undergoing open bariatric surgery: respiratory muscle strength, lung volumes and diaphragmatic excursion, Clinics 2011;66(10):17211727.

27. Uldry C, Fitting JW. Maximal values of sniff nasal inspiratory pressure in healthy subjects. Thorax 1995;50(4):371-375.

28. Villiot-Danger JC, Villiot-Danger E, Borel JC, Pépin JL, Wuyam B, Vergès S. Respiratory muscle endurance training in obese patients. Int J Obes 2011;35(5):692-699. 